pressure, the patient resumed work. The right arm remained weak, and certain movements, such as reaching an object placed at a higher level than the shoulder, were performed with increasing difficulty. Examination: 'The patient was a healthy man, of average muscular development; he has never had any illness except colds and the like. On looking at the back, the patient being erect, with the arms hanging down by his sides, the posterior borders of the scapula were seen to be equidistant and parallel to the vercebral column, the inferior angle of the right scapula being everted; there was no difference between the level of the two shoulders. When the arms were extended in front of the body the posterior border of the right scapula stood away from the thorax fully two and a half inches, well exemplifying the designation "winged scapula." The serrations of the right serratus magnus were invisibie when an attempt was made to bring the muscle into action ; in repose there was no perceptible difference between the serrati muscles of the right and left sides. There was no flattening of the right rhomboidei, nor any difference, either in action or repose, between them and the corresponding muscles of the left side. The patient could not raise the right arm above the horizontal plane except the blade of the scapula was firmly pressed against the trunk and carried outwards by the hand of a bystander. All movements were un attended with pain; the objective pain had quite disappeared. Electrical reactions : The right serratus magnus displayed fully developed reaction of degeneration, except that the faradaic irritability was not quite extinct. The rigat trapezius, levator anguli scapule, rhomboidei, and deitoid, and the whole of the muscles of the left side yielded normal reactions. Treatment : Voltaic current fourteen m. v. for ten minutes twice a week until faradaic irritabilitv re turned, when the induced current was substituted. In June the patient was discharged, the serratus having quite recovered its motility.

CASE 3.-J. Tunder my care at the out-patient department of the Salford Hospital, May 7th, 1883. He stated that about ten days previously he had been directed by his master to assist in the internal decoration of a number of cottages ; the duty allotted to him was that of whitewashing ceilings, a kind of work with which he was practically unaequainted. The patient worked a couple of days, during which time he had to desist frequently for short intervals from sheer fatigue of the arm. The right arm alone was used, as the patient, a few days before, had sprained his left wrist. From want of sufficient elevation he was obliged to keep the arm at full stretch all the time he was at work. On the third day he experienced much greater difficulty in accomplishing his task, and on that day left his work unfinished. The following day he had a good deal of diffuse pain and soreness in the arm and shoulder, but no shooting pains nor muscular twitchings; the pain rapidly subsided, leaving a feeling of weakness in the shoulder. Examination: The patient was under-sized and ill-nourished, but had not suffered from any illness other than the minor ailments of childhood. With the arms pendent the seapulio were nearly parallel to, and equidistant from, the vertebral column, the inferior angle of the right scapula being slightly nearer the middle line than that of the left, and everted to the extent of about half an inch. The costal attachments of the right serratus were invisible on deep inspiration, but tnere was no atrophy. With the arms horizontally forwards the internal border of the right scapula stood away about an inch and a half from the thorax. On being told to lift his arms above the head, he only partially succeeded with the right; when elevated the right arm was further away from the head than the left, the latter being applied close to the left ear. Electrical examination: Voltaic and fradaic irritability of the right serratus magnus was considerably lessened, but there were no qualitative changes in the reactions; all the other muscles responded normally. Treatment : Rest was enjoined for a week, after which the faradaic current was used for six or eight minutes twice a week. The recovery was rapid and complete; in six weeks the patient was discharged cured. This case was one of prresis rather than paralysis of the serratus magnus, the inuscle, I have reason to suppose, not being completely enervated, it will therefore not be included amongst the cases referred to when commenting on the symptoms of serratus paralysis.

In the first of these cases the mischief seems to have been occasioned through implication of the posterior thoracic nerve just before it pierces the scalenus medius, in the mass of indurated tissues surrounding the inflamed cervical glands. My friend Dr. Ross, who kindly saw the case with me, concurred in this opinion. The neuralgic pain on the back of the head was probably due to irritation from the same cause, of one of the superficial branches of the great occipital nerve. In Case 2 the nerve in its superficial position in the neck was probably severely compressed by the heavy pieces of metal, and more or less neuritis set up, as indicated by the pain along the course of the nerve and coincident muscular twitchings. The etiology of the third case is more difficult of explanation. Eliminating cold as a causeand careful inquiry failed to elicit any history of such causation-two hypotheses present themselves: fatigue of the muscle, or injury to the posterior thoracic nerve as it perforates the scalenus medius through forcible muscular contraction. It is difficult to understand how muscular fatigue of such a limited duration could cause paralysis in one muscle only of those concerned in the production of the movements which gave rise to the fatigue. Why should the trapezius and deltoid escape? The second hypothesis also presents difficulties. When the vertebrie are the fixed point the scaleni assist in elevating the ribs; in ordinary respiration their action is very slight; when their lower attachments are the fixed point the muscles draw the head sideways. It is possible that in flexing the neck strongly to the left, as would be done in an endeavour to reach a high vertical plane with the right arm, the right scaleni would be rendered very tense, and that continuous movements of the right arm under these conditions might injure the nerve and produce in it some molecular change sufficient temporarily to interfere with its conductivity. Jobert de Lamballe ${ }^{1}$ mentions the case of a ropemaker who suffered from a serratus paralysis through working with the aros vertically above the head. Weisner ${ }^{2}$ also mentions the same causation. In my case, from the character of the symptoms, the electrical reactions, and the speedy recovery, it appears improbable that neuritis was set up, or that the axis cylinder was injured. $\mathrm{Erb}^{3}$ has proved experimentally that after contusion of a peripheral nerve the axis cylinder may persist, the resulting degeneration being confiued to the medullary substance. Motor nerves are known to afford less resistance than sensory nerves to the effects of pressure. Weir Mitchell ${ }^{4}$ states that a pressure equal to eighteen or twenty inches of mercury exerted for fifteen minutes is sufficient to completely interrupt the conduction of motor influences for a time, the conductivity returning soon after the pressure is removed.

$$
\text { (To be concluded.) }
$$

\section{NOTE ON WASHING OUT THE URINARY BLADDER.}

BY W. J. COLLINS, M.D., B.S., B.Sc. LOND.

THeRe are few things among minor surgical therapentics that may be so conducive to the patient's comfort, when properly performed, as washing out the urinary bladder. But to be efficient it requires much care and gentleness in management, and I cannot help thinking that most of the methods at present in vogue are open to the twofold objection of awkwardness of execution and risk of introduction of air. The old method of throwing in several ounces of water from a brass syringe through a silver catheter has received Sir H. Thompson's just condemnation. These have been superseded by gentler appliances in the shape of the flexible catheter and the indiarubber bottle with a brass nozzle and stopcock, and valuable improvements they undoubtedly are. It is, however, somewhat diffealt to accurately fill the bottle, and air is often heard to escape with a bubble when the contents are injected; moreover, the nozzle has to be withdrawn from the catheter after park injection to give exit to the effluent from the bladder. This latter objection has been surmounted by employing a dnutile current catheter, the only drawback from which is that the channel is thereby halved, and so the exit of tiakes of mucopus or portions of blood-clot is hindered or prevented.

The following plan, which I have adopted, is simple and

1 Gaz des Hôpitaux, 1845. 2 Dentsches Arch. f. Klin. Med., Bd. 5. 4 Injuries of Nerres and their Consequences, 1872. 
handy, and is, I think, free from the objections stated above. The only really new feature in the apparatus is a vulcan ite two-way tap, which Messrs. Arnold and Sons have kindly made for me. This tap I attach to an ordinary siphon enema; one nozzle is for insertion into the catheter; with the other, or waste tap (B), a piece of indiarubber tubing is connected to conduct away the effluent from the bladder. The catheter employed should be, where preference is possible, a large indiarubber one, but the nozzle of the tap is tapered so as to fit several sizes. ${ }^{1}$ In order to use the apparatus any residual urine is first evacuated by the catheter; the latter then remains full of urine. The enema and tap are previously immersed in the fluid to be injected, which is worked through the enema (the waste tap being turned off) a few times to expel all air, and the tap turned off while below the surface. The whole is then entirely free from air, the nozzle is pushed into the catheter, the stopcock of A turned on, and the ball of the enema slowly and gently squeezed empty of its contents; by this means from one ounce and a half to two ounces have been injected; the afferent tap is then turned off, the waste opened, and the process repeated as often as necessary. The tap is made of vulcanite, which is superior to brass, as it is much lighter, and so does not tend to drag the catheter out by its weight. I have employed this method of irrigation in a great many cases in

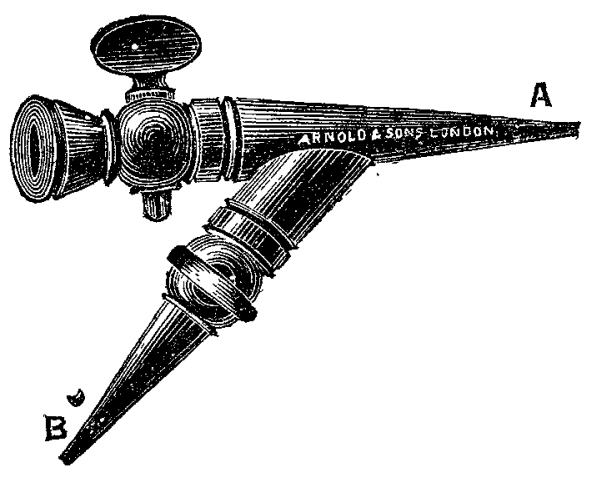

both sexes, and am fully satisfied with its convenience and efficacy. Water at the temperature of the body, to which a few drops of Condy's fluid have been added, I have found the most efficient and least irritating of all injections that have been recommended, superior even to carbolic acid and to quinine, the use of which is apt to be followed by some vesical tenesmus and discomfort.

As regards the quantity to be injected, distension of the bladder is of course unnecessary and harmful ; the habitually slow distillation of urine should be remembered; at the same time it would appear that the condition of an empty bladder is one not of tonic contraction, but of passive collapse, I think, bearing these facts in mind, that the gradual and cautious injection of about two ounces of fluid at a time is a safe and practicable mean.

The relief which follows the evacuation of irritating and offensive residual urine, and the cleansing of the unhealthy and chronically inflamed membrane, is of ten truly marvellous; and I feel sure that the occasional judicious washing of the bladder in cases of chronic catarrh or low inflammation of that organ does much to prevent the extension of inflammation upwards, and so prolong life, while it greatly adds to the comfort of the patient, and for these reasons might be more frequently resorted to than is usual in such cases.

Regent's-park, N.W.

\section{ON THE}

\section{TREATMENT OF THE PERINEUM IN PREG-} NAN'T AND PARTURIENT WOMEN.

BY WILLIAM A. DUNCAN, M.D., F.R.C.S. ENG., OBSTETRIC PHYSICIAN TO THE ROYAL HOSPITAL FOR DISEASES OF CHILDREN AND WOMEN.

'THE impertance of the perineal body in helping to maintain the female reproductive organs in a healthy condition, and the numerous ill effects arising from its partial or complete rupture, are, I think, not sufficiently recognised by many medicalmen, though they are constantly being brought prominently

1 In the cut the nozzles are represented rather too conical; it is important, for the reasons given above, to have the bore as large as possible. under the notice of gynrcologists. During the last fifteen months many women have attended the out-patient depart ment of St. Thomas's Hospital suffering from various dis. orders, due, it appears to me, to the $\mathrm{lo} \mathrm{s}$, in a greater or less degree, of the support of the perineum. As prevention is better than cure, thess few remarks are written in the hope that they may induce my brother practitioners never to jgoore a laceration, however slight, of the perineum.

1. During pregnency.-It must nece:surily seldom happen that we are called upon to operate on a ruptured perineum, for as a rule the patient oeeks advice before she again becomes pregnant. In the following case, however, the dis. comforts due to the rupture were so aggravated by the gravid state as to compel the woman to apply for help. Mrs. J_ared twenty.one, attended the hospital on Nov. 4 th, 1882, and gave the following history: Has been married four years; has two children ; first child was delivered with instruments. The perineum was ruptured, but reunited by wire sutures. In the second confinement (Jan. 29th, 1882 ) the perineam was again torn, but nothing was done to restore it. Since then the patient has suffered more or less from incontinence of faces, and this trouble has greatly in. creased during the last three months, together with a constant sense of bearing down and backache. Catamenia have not appeared for three months. There has been some morning sickness, but patient positively asserts she is not pregnant. On examination, there is found a complete rupture of the perineum, extending through the sphincter ani and for half an inch up the recto-vaginal septum. The uterus is low in the pelvis and somewhat retroverted; bimanually, it is about as large as a small cocoa-nut. Notwithstanding that the patient was pregnant, I advised her to come into the hospital for an operation, to which she consented, and, with Dr. Gervis's kind permission, I took charge of the case. On Nov. 16th, the patient being under the influence of ether, I closed the rent in the septum, reunited the divided sphincter ani and the perineum, taking care to make the bases of the triangular raw surfaces unusually wide, and not extending the apices quite as high as usual. Four deep wire sutures with bars were used, and the superficial edges brought together with catgut. A self-retaining catheter was intro. duced into the bladder, a half-grain morphia suppository into the rectum, and the knees securely tied together. The operation lasted an hour and a half. The further progress of the case is briefly as follows. There was a good deal of sickness after the anresthetic. An opium pill was given every night to keep the bowels quiet until the 23rd (seven days after the operation); then a warm oil enema was administered, and when the bowels had acted the deep wire sutures and the catheter were removed. The perineum was found to be firmly and completely united; no cystitis. The patient's stay in the hospital was prolonged by an attack of bronchitis. She was discharged cured on Dec. 14th, feeling perfectly well, and with absolute control over the fæces. She came to see me at intervals, and continued well. At 10 P.M. on June $23 \mathrm{rd}, 1883$, labour pains set in, and the patient was de. livered, ten hours and a half later, of a healthy male child. The perineum sustained no damage whatever.

Remarls. - This case is interesting, showing as it does that a pregnant woman may undergo rather prolonged ancesthesia, together with an operation on the generative organs, without interference with the pregnancy. Other severe operations have been performed without ill effect, at various stages of preguancy, by Sir Spencer Wells, Mr. Cooper Forster, Professur Schroeder, and others; but, as far as I have been able to ascertain, there is no case recorded of perineoraphy in a similar condition which would help us in answering the question, How soon after union is a perineum likely to successfully bear the strain to be put upon it during the ensuing labour? Many women pass through the period of pregnancy with torn perineums without much discomfort, but in the above case the operation was, I think, not only justifiable, but clearly indicated. Obviously there is some risk run of abortion resulting, and this may be brought on either from the rather severe after-aickness which almost invariably occurs after operations on the female generative organs, no matter what anasthetic be employed, or from the toxic effect of the drug on the foctus.

2. During parturition.-Numerous measures have been employed to protect the perineum during parturition, but, from observations of over five hundred cases, I have come to the conclusion that most of them (such as supporting the perineum with the hand, stretching it with the fingers, placing the patient with her legs down instead of bent up 